\title{
Insight into Combustion Sources Affecting Our Indoor Environment and Health
}

\author{
Anand Kumar and Tarun Gupta* \\ Environmental Engineering and Management Program, Indian Institute of Technology Kanpur, Kanpur, India
}

Epidemiological and experimental evidence suggests that shortterm exposure to $\mathrm{PM}_{2.5}$ (particles having an aerodynamic diameter less than $2.5 \mu \mathrm{m}$ ) over a period of few weeks-to-hours triggers both fatal and non-fatal events from cardiovascular disease (CVD), while long term exposure to $\mathrm{PM}_{25}$ over a period of months-to-years increases CVD risk and reduces life expectancy within a population by several months [1]. These ill effects depend on size, number, and chemical composition of respirable particles, which vary with different sources and anthropogenic activities [2]. Some studies indicate that people are more affected by indoor air pollution than that from outdoor air pollution, mainly due to two reasons: the indoor air pollutant levels are higher than outdoor levels; secondly as most people spend $80-90 \%$ of their time indoors [3].

There are various building components that could potentially affect the indoor air quality such as site of the building, its envelope and structural components, plumbing or sanitation facilities, ventilation system, etc. [4]. These components and facilities equipped with a variety of sources generate indoor air pollutants from places such as cooking gas ranges, fire places, cigarette smoking, household products like detergents, air fresheners, hair sprays. In addition, activities like dusting and vaccum cleaning contribute to the indoor air quality and deteriorating health of the residents. According to a report from the World Bank, particulate pollution causes 109,000 premature deaths, 7,500 deaths among children under five, and 48,000 new cases of chronic bronchitis every year [5].

In a developing country like India, the situation is far more challenging. According to Census 2011 data, 31\% of the households still use kerosene as source for lighting, $31.5 \%$ households have no separate kitchen space and they cook inside the house, $67 \%$ households use firewood/crop residue, cow dung cake/coal etc. [6]. The transition towards cleaner fuels is taking place but the rate is too slow. This poses a big threat to the health of the people living in such households especially women, children and aged members of the household. In poorly ventilated houses, indoor air pollution can exceed acceptable levels for small particles by many-folds. Inhalation exposure is particularly high among women and children spending majority of their time in the proximity of the domestic hearth.

It happens that the true personal exposure is not always represented by outdoor concentrations of pollutants as on an average people spend most of their time in indoor microenvironments [7]. The agenda remains that there is a need to understand and quantify indoor air pollutants especially particulate matter which contribute to the deterioration of health of the household dwellers. According to a study done in north central region of India, the outdoor sources as well as indoor activities influence the coarse and especially the fine particulate concentrations of indoors in houses located in different microenvironments in all the seasons with highest concentrations found during winter season primarily due to increased fuel usage for space heating [8]. There have been some recent studies exploring the effect of human activities on personal exposure. In another study, high concentrations of the different fractions of particulates and black carbon were observed inside auto-rickshaws in New Delhi, India [9]. The pollutant concentration can change appreciably due to different indoor sources and ventilation patterns within varying microenvironments. Outdoor concentrations would dominate over indoor concentrations only in presence of good ventilation system as that would result in high air exchange rates [10].

There have been a few studies done lately on a typical college environment and analyzing personal exposure of particulate matter and pollutant gases in different micro-environments. A study done at IIT Kanpur showed that the time a student spent in different microenvironments such as hostel mess, classroom, canteen, etc. with elevated exposure was too low to cause any serious problems for a healthy adult except eye irritation and at times coughing. However, when a student goes on an outdoor trip, the elevated exposure persists for 4-6 hours which may cause eye and upper throat irritation to healthy students and may contribute to lung diseases like asthma and bronchitis [2].

Tobacco smoking (in form of cigarette, cigar, biri, snuff, etc.) has become a problem at a global scale. In India, smoking inside and outside homes and work place is quite common these days. Apart from the ill effects of the smoke, the tobacco also contains heavy metals such as $\mathrm{Cd}, \mathrm{Ni}, \mathrm{Pb}, \mathrm{Cu}, \mathrm{Cr}$ etc. These heavy metals constitute the inorganic components of the tobacco. This is harmful not only for the active smokers but for the passive smokers as well because these metals prove to be toxic even at low levels as they easily penetrate into the deeper parts of our respiratory system upon inhalation. Indian cigarettes have more concentration of $\mathrm{Cr}$ and $\mathrm{Ni}$, comparable concentration of $\mathrm{Cd}$ and $\mathrm{Cu}$ and lower concentration of $\mathrm{Fe}$ and $\mathrm{Zn}$ compared to that studied in other countries [11]. A study conducted at IIT Kanpur suggests that cigarette smoking and burning incense sticks, mosquito coils and dhoop emits respirable particulate matter and toxic metals (lead, cadmium and zinc) which contribute to air pollution in a sustained manner due to their longer burnout duration [12].

Burning incense, a popular cultural practice in Indian subcontinent and elsewhere, generates respirable particulate matter and a large number of health-damaging and carcinogenic air pollutants including volatile organic compounds (VOCs) such as formaldehyde, benzene, 1,3 butadiene, styrene that may cause inflammation in human lung cells. Burning incense sticks and wood in marriages is common as well. A study conducted at Raipur, Chhattisgarh shows high emission factors for $\mathrm{CO}_{2}$ and benzene for wood, cow dung, semi-clarified butter milk, and Hawan material used in marriage ceremonies [13].

It can be concluded that there is an immediate need to conduct indepth studies looking carefully at the issues of both urban and rural indoor air pollutants including their monitoring, comprehensive

*Corresponding author: Tarun Gupta, Environmental Engineering and Management Program, Indian Institute of Technology Kanpur, Kanpur, India, E-mail: tarun@iitk.ac.in

Received October 19, 2013; Accepted October 21, 2013; Published October 27, 2013

Citation: Anand Kumar, Tarun Gupta (2013) Insight into Combustion Sources Affecting Our Indoor Environment and Health. J Civil Environ Eng 3: e113. doi:10.4172/2165-784X.1000e113

Copyright: (c) 2013 Anand Kumar, et al. This is an open-access article distributed under the terms of the Creative Commons Attribution License, which permits unrestricted use, distribution, and reproduction in any medium, provided the original author and source are credited. 
Citation: Anand Kumar, Tarun Gupta (2013) Insight into Combustion Sources Affecting Our Indoor Environment and Health. J Civil Environ Eng 3: e113. doi:10.4172/2165-784X.1000e113

Page 2 of 2

investigation of their sources, physic-chemical nature, relative toxicity and their variation with indoor facilities such as ventilation etc.

\section{References}

1. Bhatnagar A (2011) Environmental Cardiology: Pollution and Heart Disease. Royal Society of Chemistry, Cambridge, UK.

2. Devi JJ, Gupta T, Tripathi SN, Ujinwal KK (2009) Assessment of personal exposure to inhalable indoor and outdoor particulate matter for student residents of an academic campus (IIT-Kanpur). Inhalation Toxicology 21: 12081222.

3. Spengler JD, Sexton K (1983) Indoor air pollution: A public health perspective. Science 221: 9-17.

4. Spengler JD, Samet JM, McCarthy JF (2001) Indoor Air Quality Handbook. McGraw-Hill, USA.

5. World Bank (2013) India - Diagnostic assessment of select environmental challenges, Volume 1. An analysis of physical and monetary losses of environmental health and natural resources.

6. Census (2011) Ministry of Home Affairs- Government of India.

7. Clayton CA, Perritt RL, Pellizzari ED, Thomas KW, Whitmore RW, et al. (1993) Particle Total Exposure Assessment Methodology (PTEAM) Study:
Distributions of aerosol and elemental concentrations in personal, indoor, and outdoor air samples in a southern California community. Journal of Exposure Analysis and Environmental Epidemiology 3: 227-250.

8. Massey D, Kulshrestha A, Masih J, Taneja A (2012) Seasonal trends of PM10 PM5.0, PM2.5 \& PM1.0 in indoor and outdoor environments of residential homes located in North-Central India. Building and Environment 47: 223-231.

9. Apte JS, Kirchstetter TW, Reich AR, Deshpande SJ, Kaushik G, et al. (2011) Concentrations of fine, ultrafine, and black carbon particles in auto-rickshaws in New Delhi, India. Atmospheric Environment 45: 4470-4480.

10. Devi JJ, Gupta T, Rajmal J, Tripathi SN (2013) Measurement of personal and integrated exposure to particulate matter and co-pollutant gases. Environmental Science and Pollution Research 20: 1632-1648.

11. Verma S, Yadav S, Singh I (2010) Trace metal concentration in differen Indian tobacco products and related health implications. Food and Chemical Toxicology 48: 2291-2297.

12. Roy AA, Baxla SP, Gupta T, Bandyopadhyaya R, Tripathi SN (2009) Particles emitted from indoor combustion sources: Size distribution measurement and chemical analysis. Inhalation Toxicology 21: 837-848.

13. Dewangan S, Chakrabarty R, Zielinska B, Pervez S (2013) Emission of volatile organic compounds from religious and ritual activities in India. Environmental Monitoring and Assessment 185: 9279-9286. 